\title{
« Legal Advertising and Frivolous Lawsuits »
}

\author{
$\underline{\text { Auteurs }}$ \\ Yannick Gabuthy, Eve-Angéline Lambert
}

Document de Travail $\mathrm{n}^{\circ} 2018-03$

Bureau d'Économie

Théorique et Appliquée

BETA - UMR 7522 du CNRS

\section{BETA Université de Strasbourg}

Faculté des sciences

économiques

et de gestion

61 avenue de la Forêt Noire

67085 Strasbourg Cedex

Tél. : +33 (0)368 852069

Fax : +33 (0)3 68852070

Secrétariat : Géraldine Del Fabbro

g.delfabbro@unistra.fr

\section{BETA Université de Lorraine}

Faculté de droit, sciences

économiques

et de gestion

13 place Carnot C.O. 70026

54035 Nancy Cedex

Tél. : +33(0)37274 2070

Fax : +33 (0)3 72742071

Secrétariat : Sylviane Untereiner sylviane.untereiner@univ-lorraine.fr

Janvier 2018

http://www.beta-umr7522.fr 


\title{
Legal Advertising and Frivolous Lawsuits*
}

\author{
Yannick Gabuthy ${ }^{\dagger} \quad$ Eve-Angéline Lambert ${ }^{\ddagger}$
}

September 2017

\begin{abstract}
Following a recent wave of deregulation, lawyers now use a large variety of media to advertise their services. A common argument against this increasing reliance on advertising is that it might stir-up frivolous lawsuits. In this article, we investigate the theoretical relevance of this argument by developing an asymmetric information game of litigation where the likelihood of accident and the number of lawsuits are endogenous. The main result shows that this stirring-up effect does not necessarily occur in equilibrium since the impact of advertising on meritless claims results from complex strategic effects arising in the litigation game. In the same way, the welfare analysis highlights that advertising may increase or decrease the social cost of accidents. These results imply that the recent trend toward liberalization of legal advertising should not necessarily be considered as a threat to the efficiency of the tort system.
\end{abstract}

Keywords: Litigation, Advertising, Deterrence, Frivolous lawsuits.

JEL codes: K13, K41, M37.

\footnotetext{
${ }^{*}$ We wish to thank two anonymous referees, Tim Friehe, and the participants to the MACIE research seminar (University of Marburg) and BETA seminar (University of Strasbourg and University of Lorraine) for their useful comments.

${ }^{\dagger}$ Corresponding author; BETA (CNRS, University of Strasbourg, University of Lorraine); 13, place Carnot, C.O. 70026, 54035 Nancy, France. Email: yannick.gabuthy@univ-lorraine.fr. Phone number: +33 (0) 372742084 .

${ }^{\ddagger}$ BETA (CNRS, University of Strasbourg, University of Lorraine); 13, place Carnot, C.O. 70026, 54035 Nancy, France. Email: eve-angeline.lambert@univ-lorraine.fr. Phone number: +33 (0) 372 742082 .
} 


\section{INTRODUCTION}

2 Advertising is now widely used by lawyers as a way to promote their services, through 3 various media such as press, television, radio, the yellow pages and the internet. In4 deed, following a recent wave of deregulation, restrictions on lawyer advertising 5 have been broadly relaxed in several jurisdictions, implying an increasing reliance 6 on advertisement by legal profession. For instance, in the U.S., advertising expen7 ditures grew sharply over the first decade of the 21st century: law firm advertising 8 generated $\$ 575$ million in TV revenues in 2006, and TV advertising expenditures 9 increased from $\$ 236$ million in 2000 to $\$ 493$ million in 2009 (Stone and Miceli, 2012;

10 Tuil and Visscher, 2010), knowing that a similar trend is observed regarding press 11 and radio/internet. In the same way, in France, lawyers may advertise since 2005 12 but some restrictions have been removed by the law adopted in March $2014 .^{1}$ In 13 England and Wales, solicitations are also permitted with few limitations, including 14 a prohibition of comparative advertisement. ${ }^{2}$

15 Overall, the most standard type of legal advertisements are those by tort lawyers, 16 whose field of law includes personal injury, medical malpractice, and product liability 17 cases, all of them involving compensation for damages. In this regard, a common 18 argument against the increasing use of advertising is that it might stir-up frivolous

\footnotetext{
${ }^{1}$ Décret no. 2014-344, dating from $17^{\text {th }}$ March 2014, over consumption.

${ }^{2}$ See Stone and Miceli (2012) for a wide and interesting description of the present regulatory frames existing in different jurisdictions around the world.
} 
1 coffee case. $^{3}$ In this context, the issue of frivolous litigation - as a major waste of 2 resources - has inspired some of the most significant procedural developments in the U.S. over the last decades. In 1983, for instance, the Advisory Committee on Civil Rules overhauled Rule 11 of the Federal Rules of Civil Procedure to strengthen sanctions on individuals who present in court a "pleading, written motion, or other paper" that is deemed to be frivolous. Furthermore, Willging (1988) reports that over half of cases under 1983 Rule 11 involved the filing of an unjustified complaint. More recently, the Private Securities Litigation Reform Act that was entertained by 9 the American Congress in 1995 contains a number of provisions designed to reduce 10 frivolous class actions (Bone, 1997; Choi, 2007). In the same perspective, scholars 11 and policymakers recognize that the introduction of the so-called English fee-shifting 12 rule in Europe aimed indirectly at deterring meritless suits. Indeed, this rule implies 3 fee-shifting in favor of the winning litigant and, hence, should deter low-probability14 of-success lawsuits by making non-indigent plaintiffs more risk-adverse (Carbonara 15 et al., 2015).

16 In this regard, the aim of our paper is to analyze - from a theoretical standpoint 17 whether attorney advertising promotes frivolous litigation, and is detrimental to so18 cial welfare in a broader way. We investigate this issue by developing an asymmetric 19 information game of litigation and settlement à la Katz (1990), where defendants 20 cannot observe the real loss suffered by victims, which explains that meritless suits 21 may both arise and succeed in reaching settlements. However, we go beyond this 22 paper both by making the probability of accident endogenous and by incorporating

\footnotetext{
${ }^{3}$ See Liebeck v. McDonald's Restaurants, Docket No. D-202 CV-93-02419, 1995 WL360309 (Bernalillo County, N.M. Dist. Ct. August 18, 1994).
} 
advertising may lessen the individual incentives to file meritless claims, which arises because of the asymmetric information setup. Furthermore, our results show that advertising may also reduce the expected number of frivolous suits by encouraging the injurer to be more careful in order to reduce the likelihood of accident and litigation. Following this second strategic effect, it would be misleading to evaluate the potential stirring-up effect of advertising by considering an exogenously given accident rate. To summarize, the overall impact of advertising on frivolous suits is ambiguous and may be counterintuitive on an a priori basis, since it results both from a direct effect on the expected number of potential plaintiffs and from strategic effects due to the interactions arising in the game played by the parties. This ambiguity translates in the welfare analysis which highlights that advertising may increase or decrease the social cost of accidents. Therefore, from a policy perspective, the prohibition of advertising which is still in effect in some countries (e.g. Croatia, Romania) cannot be optimal in a general sense, and the recent trend toward liberalization of legal advertising should not necessarily be assessed as a threat to the efficiency of the tort system.

The potential influence of lawyer advertising on frivolous litigation has been overlooked in the literature, which essentially evaluates the effect of advertising on the price and quality of legal services from an empirical viewpoint. Following the seminal paper by Stigler (1961), several analyses conclude that the deregulation of advertising enhances competition and, hence, is welfare improving (see, e.g., Schroeter et al., 1987). Indeed, according to Stigler's argument, advertising provides information and, thus, reduces consumers' search costs, implying that it should have pro-competitive consequences. More specifically, an extensive empirical literature highlights that restrictions on advertising increase the fees charged for the profession's services, which may damage the reputation of lawyers (Stephen and Love, 1996). However, from a theoretical perspective, our analysis is deeply connected to the articles by Stone and Miceli (2012) and Miceli and Stone (2014). To summarize, the latter paper examines whether frivolous litigation may enhance deterrence by encouraging potential injurers to increase their level of care (but it does not incorporate the possibility of advertisement on legal services), while the former analyzes the efficiency of lawyer advertising in terms of litigation costs and deterrence (but it rules out the existence of frivolous lawsuits). Our paper complements these studies by addressing the effect of advertising on frivolous litigation, through its impact on care decisions. 
1 The remainder of the paper is organized as follows. Section 2 lays down the formal 2 structure of the model. Section 3 presents the results regarding the equilibrium 3 strategies and welfare analysis. Section 4 investigates some extensions of the basic 4 framework, and Section 5 concludes by suggesting some possible extensions.

\section{2. TheORETICAL FRAMEWORK}

6 This section develops a model of the influence of lawyer advertising on the litigation 7 process and the operation of the tort system, in which the sequence of events is as 8 follows (and summarized in the appendix).

9 At date 1, a representative lawyer may advertise to a set of potential victims who, 10 with some probability, will be injured in an accident. The number of potential 11 victims is normalized to one, without loss of generality, and the advertising intensity, $12 a$, implies a cost for the lawyer that is equal to $h(a)$, where $h^{\prime}>0$ and $h^{\prime \prime}>0$.

13 At date 2, given the decision previously made, the potential injurer chooses his level 14 of care, $x$, which determines the probability of accident $p(x)$, where $p^{\prime}<0$ and $15 p^{\prime \prime}>0$. The level of care, $x$, induces a cost $k(x)$ for the injurer, with $k^{\prime}>0$ and $16 \quad k^{\prime \prime}>0$. The game ends if no accident arises.

17 At date 3 , the accident victim is actually injured with some probability $\beta \in(0,1)$. ${ }_{18}$ We consider an incomplete information setup where the potential plaintiff knows whether or not she suffered harm, while the defendant cannot know the plaintiff's genuineness ex-ante. ${ }^{4}$ This setup may be illustrated by considering the following simple hypothetical situation (Katz, 1990): one day while shopping at a retail store, a customer falls on a floor that the store negligently failed to keep dry. The customer knows with certainty whether she sustained some injury, but the store only knows that such falls result in injury some proportion of the time.

At date 4 , the accident victim - whether injured or not - makes a decision about filing a suit, at cost $f$, depending on whether she has been exposed to the lawyer's advertising. The amount $f$ includes the cost of preparing a complaint and making the defendant aware of the lawsuit. We assume that the population of accident victims is composed of two types: the first type (i.e. type 1) is well-informed and hence aware that a lawsuit is possible if she has been injured, while the second one

\footnotetext{
${ }^{4}$ We use 'she' to refer to the accident victim/plaintiff and 'he' to refer both to the defendant and the plaintiff's attorney.
} 
1 (i.e. type 2) is uninformed and does not know how to find a lawyer, whenever she 2 has been injured or not. Let $\tau$ (resp. $1-\tau$ ) represent the fraction of type-1 (type-2) 3 plaintiffs, with $\tau \in(0,1)$. In this context, we consider that a truly injured victim 4 of type 1 is not responsive to advertisement since she knows how to find a lawyer, 5 while a genuine victim of type 2 can decide to file a suit if and only if she has 6 been previously exposed to advertisement. In contrast, we assume that a frivolous 7 plaintiff always needs advertisement to get the services of a lawyer. Indeed, from a 8 behavioral perspective, we consider that a genuine victim can be aware on her own 9 (i.e. without advertising) that a lawsuit is possible, provided that she is informed, while a frivolous victim cannot have this possibility in mind - since she has not been injured - and hence needs an advertisement to be legally represented. Furthermore, the probability that a potential plaintiff - whether injured or not - has been exposed to advertising is denoted $\alpha(a)$, where $\alpha(0)=0, \alpha(a) \in(0,1), \alpha^{\prime}>0$ and $\alpha^{\prime \prime}<0$. Therefore, following the arguments mentioned above, the overall fractions of injured and frivolous plaintiffs who are aware that a lawyer is available and, then, a lawsuit is possible are respectively:

$$
\phi(a):=\tau+(1-\tau) \alpha(a) \quad \text { and } \quad \psi(a):=\alpha(a)
$$

17 Notice that the rate of advertising exposure (i.e. $\alpha()$.$) is the same regardless of the$ plaintiff's claim (viz. frivolous or valid). Indeed, we consider that the representative lawyer is a Stackelberg leader who advertises an audience of possible clients exante (viz. before a potential accident occurs), which implies that the likelihood of exposure cannot depend on the merits of the plaintiff's case.

This framework is consistent with the informative view of advertising - which is adopted by Stone and Miceli (2012) - and implies that advertising is regarded as a 'barrier to entry' for uninformed people into the litigation process. ${ }^{5}$ However, the functions in (1) may also be consistent with an alternative view of advertising considering that advertisements may have both an informative and a persuasive/suggestive

\footnotetext{
${ }^{5}$ This framework could also capture the intuitive idea that a well-informed victim is more likely to be injured (given that $\tau>0$ ). Indeed, we could consider for example that an informed person would be less prone to take care in order to lessen the likelihood of accident - than an uninformed person - anticipating that she would easily access to legal representation if an accident occurs. In such a context, the expected probability to be injured would be higher for aware people. However, this story would be tackled more accurately by assuming that the potential victim as well as the injurer might influence the probability of accident by their levels of care (see, e.g., Shavell, 1980). This issue could be addressed in an extension of the current framework.
} 
1 role, depending on whether the victim has been truly injured or not. ${ }^{6}$ Following this 2 view, advertising would be purely informative in case of injury, which would lead to the function $\phi(a)$ stated in (1). Indeed, it seems reasonable to consider that, when a victim has been genuinely injured, the only impediment for her to be legally represented by a lawyer is a lack of information (since a genuine victim does not need, a priori, to be persuaded to hire a lawyer). In this case, the only role of advertising is to alert uninformed people of the availability of the representative lawyer's services, while advertisement is not useful for informed victims. In contrast, we could consider that an uninjured victim would need to be persuaded - regardless of the information she holds - notably because she does not have the technical skills required to understand the litigation process (and hence to believe that a frivolous claim may succeed in reaching a settlement). These arguments would imply that $\psi(a):=[\tau+(1-\tau)] \alpha(a)$ and we would get the function $\psi(a)$ stated in (1). Overall, 14 following this approach, advertising would be only informative for genuine victims, 15 but both informative and suggestive for uninjured ones. Assuming this suggestive

\footnotetext{
${ }^{6}$ See Bagwell (2007) for a broad discussion on the different roles of advertising in an economic perspective.
} 


\footnotetext{
${ }^{7}$ Following a standard assumption in literature, we consider a competitive market for legal services, implying that our results are not affected by the fee arrangement in place. Considering the US-style contingent fees in which the lawyer gets a share of the judgment in case of winning, competition would drive the contingency rate to the point where the lawyer's expected profit is zero in equilibrium. The market forces would operate the same way under UK-conditional fees.
} 
amount of the settlement offer. The analysis would be significantly more complex in a model where the informed plaintiff would make a settlement demand, serving as a signal for the defendant to infer the validity of the claim. Furthermore, as mentioned by Katz (1990), the most relevant way to incorporate asymmetric information in a theoretical analysis of litigation depends on the legal context, the type of claim and the area of substantive law. Finally, we consider that the plaintiff decides alone whether to accept the settlement offer, to refuse and drop the case or to refuse and go to trial. This view corresponds to the client-controlled litigation perspective which implicitly assumes that the client is able to control the lawyer's behavior perfectly (Hyde, 2006). This assumption enables us to abstract from the possible conflict of interest between the plaintiff and her attorney, given that the issue of lawyer control and related agency problems is analyzed in several articles and is beyond the scope of our paper (see, e.g., Emons, 2007; Emons and Garoupa, 2006).

\section{EqUILIBRIUM STRATEGIES AND WELFARE ANALYSIS}

Following our framework, although the expected return from trial is negative for frivolous plaintiffs, it may be profitable for them to file suit in the hope of extracting a settlement. Our objective is then to determine how the opportunity of advertising affects the injurer's level of care and, thus, the number of frivolous suits being filed. In order to analyze this main question of interest, we have to characterize the sequential equilibria of the game using the backward induction procedure.

3.1. Settlement-trial outcome. Given arbitrary previous choices, we begin with the stage where the plaintiff must choose between accepting the defendant's offer $S$, dropping the suit, and going to trial. A frivolous plaintiff could obtain $S-f_{s}-f$ by accepting the offer, $-\left(f+f_{s}+f_{t}\right)$ by going to trial, and $-\left(f+f_{s}\right)$ by dropping. She would therefore accept any positive offer, and would drop the lawsuit when facing a nonpositive one. In contrast, an injured plaintiff would get $l-\left(f+f_{s}+f_{t}\right)>0$ 
1 by going to trial. ${ }^{8}$ She would then accept the offer $S$ if and only if:

$$
S \geq l-f_{t}
$$

2 Notice that this threshold is independent of the plaintiff's filing cost and of the 3 lawyer's settlement fee because these costs are sunk at this stage.

4 A defendant facing a lawsuit that is potentially frivolous will then do one of two 5 things. He has the choice between offering $l-f_{t}$ that all plaintiffs will accept, 6 and proposing no settlement and going to trial against only injured plaintiffs, since 7 uninjured ones will drop their suits. Indeed, the defendant would never be well 8 advised to propose $S \in\left(0, l-f_{t}\right)$ because such an offer would be accepted by 9 frivolous plaintiffs and refused by injured ones. Since proceeding to trial costs to 10 the defendant an amount $l+c$, he strictly prefers to settle if:

$$
l-f_{t}<\hat{\beta}(l+c) \Leftrightarrow \hat{\beta}>\frac{l-f_{t}}{l+c}
$$

11 where $\hat{\beta}$ is the posterior probability that the plaintiff is truly injured conditional 12 on the fact that suit has been brought. Using the Bayes' rule, this probability is 13 defined by:

$$
\hat{\beta}:=\frac{\beta \phi(a)}{\beta \phi(a)+(1-\beta) \psi(a) \lambda}
$$

14 where $\lambda$ is the probability that a frivolous plaintiff files suit and $\beta \phi(a)+(1-\beta) \psi(a) \lambda$ 15 is the overall expected probability of filing, given the lawyer's prior choice of advertising intensity. ${ }^{9}$ Intuitively, the defendant's inference about the plaintiff's genuineness is related to $a$ - which will be defined endogenously in the model - because the screening effect of advertising depends on the merits of the case (i.e. $\phi(.) \neq \psi()$.$) .$ Following (3), the defendant will settle if and only if his updated belief on the validity of the plaintiff's claim is high enough. His optimal strategy can be then described by a variable $\theta$ which denotes the probability that he settles, while the uninjured plaintiff's optimal strategy may be characterized by the variable $\lambda$ which

\footnotetext{
${ }^{8}$ Assuming that $l-\left(f+f_{s}+f_{t}\right)$ is positive is essential to the formulation of the problem. Otherwise, neither frivolous nor injured plaintiffs file suit given that the expected return from trial is negative for both of them.

${ }^{9}$ In fact, $\lambda$ is the probability that an informed/persuaded frivolous plaintiff files suit since uninformed people cannot enter into the litigation process. This terminology is not used systematically hereafter, therefore it is important to keep in mind this screening role of advertising ex-ante.
} 
1 is the probability that she files suit. ${ }^{10}$ Overall, the behavior of uninjured plaintiffs 2 depends on their expectation of the settlement offer proposed by defendants, while 3 the strategy of defendants depends on what they expect frivolous plaintiffs to do at 4 the filing stage. It turns out that the equilibrium, which is defined by the strategy 5 profile $(\theta, \lambda)$, may be of two types.

6 The first type is a pure-strategy equilibrium and arises if:

$$
\left.\hat{\beta}\right|_{\lambda=1}:=\frac{\beta \phi(a)}{\beta \phi(a)+(1-\beta) \psi(a)}>\frac{l-f_{t}}{l+c} \Leftrightarrow \beta>\frac{\psi(a)\left(l-f_{t}\right)}{\phi(a)\left(f_{t}+c\right)+\psi(a)\left(l-f_{t}\right)}
$$

7 In this case, $\hat{\beta}>\left(l-f_{t}\right) /(l+c)$ (since $\hat{\beta}>\left.\hat{\beta}\right|_{\lambda=1}$, following (4)), which implies 8 that $\theta^{*}=1$ and $\lambda^{*}=1$. Intuitively, if the proportion of truly injured plaintiffs 9 among all suits is large enough, then the defendant intends to settle with all suitors 10 in order to avoid going to trial against injured plaintiffs (i.e. $\theta^{*}=1$ ). It follows 11 that filing a frivolous suit is profitable, since $l-\left(f+f_{s}+f_{t}\right)>0$, and hence all 12 uninjured plaintiffs file suit (i.e. $\lambda^{*}=1$ ). Overall, when (5) holds, the equilibrium 13 of the litigation game involves $\theta^{*}=\lambda^{*}=1$, with all cases settling. This equilibrium 14 will not be discussed further, essentially for two reasons. First, this outcome is a 15 corner solution which does not characterize a realistic situation. Second, the most 16 serious problem implied by this equilibrium is not the waste of litigation costs, but 17 the occurrence of unjustified wealth transfers (since all frivolous plaintiffs file suit 18 and all cases settle). Following Bone (1997), wealth transfers are unjustified when 19 a payment is made to a party who is not entitled to it, which occurs here when a 20 frivolous plaintiff obtains the settlement intended for a legitimate suit. Analyzing 21 the potential distributive consequences of advertising might be interesting but is 22 beyond the scope of our paper where the aim is to focus on efficiency considerations, 23 following the perspective adopted in a large part of the economics literature on 24 litigation.

${ }_{25}$ The second type of equilibrium arises when:

$$
\left.\hat{\beta}\right|_{\lambda=1}<\frac{l-f_{t}}{l+c}
$$

In this case, we get a mixed-strategy equilibrium in which the defendant settles with

\footnotetext{
${ }^{10}$ Recall that, since $l-\left(f+f_{s}+f_{t}\right)>0$, an injured plaintiff always files suit if she is aware of her rights.
} 
some plaintiffs and proceeds to trial with others, while some uninjured plaintiffs file 2 suit and others do not.

Lemma 1. If the proportion of truly injured plaintiffs is below a threshold level, the unique equilibrium of the litigation game, for an arbitrary value of a, is such that the likelihood of settlement and the probability that a frivolous plaintiff files suit are respectively:

$$
\theta^{*}=\frac{f_{s}+f}{l-f_{t}} \quad \text { and } \quad \lambda^{*}=\frac{\beta \phi(a)\left(f_{t}+c\right)}{(1-\beta) \psi(a)\left(l-f_{t}\right)}
$$

3 Proof. First, let us determine the values of $\theta$ and $\lambda$ such that the defendant is 4 indifferent between settling and going to trial, and uninjured plaintiffs are indifferent 5 between filing and not filing. These values are denoted $\theta^{*}$ and $\lambda^{*}$ respectively. A frivolous plaintiff is indifferent between filing and not filing when:

$$
\theta\left(l-f_{t}-f_{s}-f\right)+(1-\theta)\left(-f_{s}-f\right)=0 \Leftrightarrow \theta^{*}=\frac{f_{s}+f}{l-f_{t}}
$$

The defendant is indifferent between settling and going to trial when:

$$
l-f_{t}=\hat{\beta}(l+c) \Leftrightarrow \lambda^{*}=\frac{\beta \phi(a)\left(f_{t}+c\right)}{(1-\beta) \psi(a)\left(l-f_{t}\right)}, \text { given }(4)
$$

6 Second, let us show that the strategy profile $\left(\theta=\theta^{*}, \lambda=\lambda^{*}\right)$ is the unique equilib7 rium when $\left.\hat{\beta}\right|_{\lambda=1}<\left(l-f_{t}\right) /(l+c)$. Suppose that $\theta>\theta^{*}$. Then a frivolous plaintiff's 8 benefit from a lawsuit is positive, so that her best response is $\lambda=1$. But then the 9 defendant's best response is $\theta=0$ (because $\left.\left.\hat{\beta}\right|_{\lambda=1}<\left(l-f_{t}\right) /(l+c)\right)$, which contra10 dicts the assumption. Conversely, suppose that $\theta<\theta^{*}$. Then a frivolous plaintiff's 11 payoff from a suit is negative, so that her best response is $\lambda=0$. But then the 12 defendant's best response is $\theta=1$ (because $\left.\hat{\beta}\right|_{\lambda=0}:=1>\left(l-f_{t}\right) /(l+c)$ ), which 13 contradicts the assumption again. A similar argument shows that $\lambda \neq \lambda^{*}$ cannot 14 be an equilibrium. Therefore, there is no pure-strategy equilibrium, and $\theta=\theta^{*}$ and ${ }_{15} \lambda=\lambda^{*}$ are best responses to each other.

${ }_{16}$ Finally, to complete the derivation of the equilibrium, we need to verify that $\left(\theta^{*}, \lambda^{*}\right) \in$ $17(0,1) \times(0,1)$. Following supra note 8 (page 10$)$, we know that $l-\left(f_{t}+f_{s}+f\right)>0$ 18 by assumption, inducing $\theta^{*} \in(0,1)$ and $\lambda^{*}>0$. Furthermore, the fact that $\lambda^{*}<1$ 19 is implied by the mixed-strategy equilibrium condition in (6).

20 Using (1) and Lemma 1, we obtain the following result. 
Proposition 1. The equilibrium probability that a frivolous plaintiff files suit is a decreasing function of the advertising intensity:

$$
\frac{d \lambda^{*}}{d a}:=\frac{\beta(1-\beta)\left(f_{t}+c\right)\left(l-f_{t}\right)\left[\phi^{\prime}(a) \psi(a)-\phi(a) \psi^{\prime}(a)\right]}{\left[(1-\beta)\left(l-f_{t}\right) \psi(a)\right]^{2}}<0 \Leftrightarrow \tau>0
$$

1 This result reflects a deterrent effect of advertising on the frivolous plaintiffs' incen2 tives to enter into litigation. Indeed, following (1), the presence of well-informed 3 people (i.e. type 1) - who are not responsive to advertisements in case of injury - in 4 the overall population of potential plaintiffs implies that advertising has a stronger marginal attractive impact on the set of uninjured accident victims than on the group of harmed individuals (i.e. $\tau>0 \Rightarrow \psi^{\prime}(a)>\phi^{\prime}(a)$ ). Therefore, when adver7 tising intensity increases, the defendant is aware of this marginal effect and revises 8 downwards the probability to face a truly injured plaintiff, which lessens the frivolous 9 plaintiff's incentives to file suit in equilibrium (i.e. $\lambda^{*}$ decreases). This - bayesian 10 negative effect of advertising arises as soon as $\tau>0$.

11 Having characterized the outcome of the litigation game, we now turn to the analysis 12 of the injurer's choice of care.

22 bargaining. ${ }_{23}$ The injurer's cost-minimizing care level, $x^{*}$, is then the unique solution to the fol-

$$
k(x)+p(x)\left[\beta \phi(a)\left(\theta^{*}\left(l-f_{t}\right)+\left(1-\theta^{*}\right)(l+c)\right)+(1-\beta) \psi(a) \lambda^{*} \theta^{*}\left(l-f_{t}\right)\right]
$$

After substituting for the values of $\theta^{*}$ and $\lambda^{*}$ stated in Proposition 1, this expected cost simplifies to:

$$
k(x)+\beta p(x) \phi(a)(l+c)
$$

In other words, the cost incurred by the injurer equals exactly the amount that would be spent if only legitimate claims were brought and if all suits went to trial. Indeed, rent-seeking by strike suitors completely dissipates all the gains from settlement 
1 lowing first-order condition:

$$
-\beta p^{\prime}(x) \phi(a)(l+c)=k^{\prime}(x)
$$

2 The left-hand of (9) is the injurer's marginal benefit from an increase in care, which 3 comes from the reduction in the number of legitimate suits, while the right-hand side

4 captures his marginal cost. Furthermore, by totally differentiating this first-order 5 condition with respect to $x^{*}$ and $a$, we get the following result.

Lemma 2. The equilibrium level of care is an increasing function of the advertising intensity:

$$
\frac{d x^{*}}{d a}:=-\frac{\beta p^{\prime}\left(x^{*}\right) \phi^{\prime}(a)(l+c)}{\beta p^{\prime \prime}\left(x^{*}\right) \phi(a)(l+c)+k^{\prime \prime}\left(x^{*}\right)}>0
$$

6 The intuition behind this result is straightforward. As highlighted above, in the 7 mixed-strategy equilibrium, the litigation process unfolds as if only valid claims 8 were brought. Moreover, an increase in lawyer advertising has a marginal attractive 9 impact, captured by $\phi^{\prime}$, on the set of injured accident victims. The only way to 10 lessen this effect for the injurer is to increase his level of care in order to reduce 11 the likelihood of accident. From a social perspective, this deterrent effect makes 12 advertising desirable as a mechanism of prevention by encouraging potential injurers 13 to internalize the risk of accident more efficiently. However, notice that an increase 14 in the share of well-informed plaintiffs $($ i.e. $\tau$ ) would undermine this deterrent effect: 15 ceteris paribus, $d x^{*} / d a$ remains positive but decreases when $\tau$ increases (since $\phi^{\prime}($. 16 is lower and $\phi($.$) is higher). Indeed, this type of injured victims does not need an$ 17 advertisement to hire a lawyer and file a suit. Therefore, the marginal attractive 18 impact of advertising is lower when this type is more prevalent in the population, 19 which makes its positive effect on the care level less strong.

Using previous results and defining $\Omega(a)$ as the equilibrium number of frivolous suits for a given value of $a\left(\right.$ i.e. $\left.\Omega(a):=(1-\beta) p\left(x^{*}\right) \psi(a) \lambda^{*}\right)$, we get the following insight.

Proposition 2. The advertising intensity has an ambiguous impact on the equilibrium number of frivolous suits:

$$
\frac{\partial \Omega}{\partial a}:=\underbrace{(1-\beta) p\left(x^{*}\right) \psi^{\prime}(a) \lambda^{*}}_{(i,+)}+\underbrace{(1-\beta) \psi(a)\left[p^{\prime}\left(x^{*}\right) \frac{d x^{*}}{d a} \lambda^{*}+p\left(x^{*}\right) \frac{d \lambda^{*}}{d a}\right]}_{(i i,-)} \gtreqless 0
$$


1 Notice that '+' (resp. '-') stands for the case where the term is positive (resp. 2 negative). Indeed, following $(i)$, advertising intensity increases the expected number 3 of frivolous suits by attracting new clients (i.e. $\psi^{\prime}(a)>0$ ). However, as shown by 4 (ii), advertisement also reduces the likelihood of frivolous claims both through its 5 positive impact on the level of care (i.e. $d x^{*} / d a>0$ ) - which lessens the probability 6 of accident - and via its deterrent effect on the uninjured plaintiffs' incentives to 7 litigate (i.e. $d \lambda^{*} / d a<0$ ). Furthermore, following the arguments mentioned above, 8 the fraction of type-1 plaintiffs (i.e. $\tau$ ) may affect the sign of $\partial \Omega / \partial a$ since an increase 9 in the number of aware people would mitigate the positive impact of advertising on $10 x^{*}$ (see Lemma 2).

11 Overall, this proposition mitigates the arguments exposed by Stone and Miceli 12 (2012) when discussing informally the potential impact of advertisement on frivolous ${ }_{13}$ lawsuits. ${ }^{11}$ Indeed, the authors consider that advertising should increase the number 14 of filed cases - whether legitimate or not - and neglect the strategic effects mentioned 15 above. From this perspective, we consider our result as interesting by highlighting

${ }^{11}$ See Section 4.2 on pp.335-36 of their paper.

Given this equation, advertising lessens the rate of frivolous cases if its direct attractive impact on the pool of potential clients, which is captured by $(i)$, is more than offset by the decrease in the number of accidents and in the equilibrium probability of frivolous suit, as highlighted by $(i i)$ and (iii) respectively. Following the arguments exposed in Section 2, the direct attractive effect may rely on the suggestive power of advertising: if accident victims turn to be highly responsive to advertisements, this effect is likely to be important, since $\psi^{\prime}($.$) will be high for a given value$ of $a$. As underlined by some studies, this capacity of persuasion may depend on the population structure: Engstrom (2011) shows that low-income/least educated 
people are more inclined to be influenced by advertising. Therefore, following the categorization by Hadfield (2000), we conjecture that the left-hand side of (10) is lower for corporate clients, implying that advertising is more likely - ceteris paribus - to reduce frivolous suits in this segment of the market for lawyers. ${ }^{12}$ The empirical relevance of the indirect effects - highlighted in the right-hand side of (10) - is more difficult to evaluate because these effects depend on strategic/behavioral responses of injurers/defendants. Indeed, in our setup, decisions are part of a sequential equilibrium which arises only if players are sufficiently sophisticated decision-makers (viz. capable of complex game-theoretic reasoning): the level of care will be boosted by advertisements (i.e. $\left.d x^{*} / d a>0\right)$ only if injurers are aware of the causality between advertising and litigiousness in the judicial system; the bayesian effect (i.e. $\left.d \lambda^{*} / d a<0\right)$ arises only if defendants both understand the victims' incentives to file suit and are able to revise their prior belief of facing an injured plaintiff accordingly. It is obviously difficult to anticipate behavior in the field on the sole basis of a purely theoretical analysis and some empirical investigations, using for example laboratory experiments, should be helpful.

Moving backwards to date 1 , we now determine the lawyer's choice of advertising intensity.

3.3. Advertising decision. At date 1, the attorney chooses the level of advertisement, taking the equilibrium level of care as given. The lawyer's expected profit is given by the following expression:

$$
p\left(x^{*}\right)\left[\beta \phi(a)\left(\left(f_{s}-c_{s}\right)+\left(1-\theta^{*}\right)\left(f_{t}-c_{t}\right)\right)+(1-\beta) \psi(a) \lambda^{*}\left(f_{s}-c_{s}\right)\right]-h(a)
$$

Assuming a competitive market for legal services, we consider that the lawyer chooses his level of advertising to maximize his expected profit, while both the settlement and trial fees (i.e. $f_{s}$ and $f_{t}$ resp.) adjust until this return is zero. The attorney's profit-maximizing advertising intensity, $a^{*}$, is then the unique solution to

\footnotetext{
${ }^{12}$ Hadfield (2000) considers that the market for lawyers in the U.S. is stratified following two segments, depending on the character of the clients served. The corporate segment is characterized by business clients and repeat purchasers, while the personal sphere consists in individual clients. Notice that Kritzer (1990) provide some data regarding major differences between these two segments.
} 
the following first-order solution:

$$
\begin{aligned}
\overbrace{p\left(x^{*}\right)\left[\beta \phi^{\prime}(a) \eta+(1-\beta) \psi^{\prime}(a) \lambda^{*} \gamma\right]}^{(i)}=-\overbrace{p^{\prime}\left(x^{*}\right) \frac{d x^{*}}{d a}\left[\beta \phi(a) \eta+(1-\beta) \psi(a) \lambda^{*} \gamma\right]}^{(i i)} & -\underbrace{(1-\beta) p\left(x^{*}\right) \psi(a) \frac{d \lambda^{*}}{d a} \gamma}_{(i i i)}+\underbrace{h^{\prime}(a)}_{(i v)}
\end{aligned}
$$

1 where $\eta$ is the lawyer's expected payoff when the client's claim is legitimate (i.e. $\left.2 \eta:=f_{s}-c_{s}+\left(1-\theta^{*}\right)\left(f_{t}-c_{t}\right)\right)$, while $\gamma$ stands for his payoff if the suit is frivolous 3 (i.e. $\left.\gamma:=f_{s}-c_{s}\right)$. Overall, following a standard interpretation, the left-hand side of 4 (12) is the lawyer's marginal return from an increase in advertising intensity, while 5 the right-hand side represents the corresponding marginal cost. The term $(i)$ is the 6 marginal increase in profit resulting from the attractive effect of advertisement on 7 the set of potential clients (whether injured or not). The expression (ii) reflects 8 the marginal indirect and negative impact of advertising on the attorney's profit, 9 via its effect on the injurer's care level: advertisement increases the level of care 10 and, hence, lowers the likelihood of accident which, in turn, decreases the number 11 of potential clients, entailing an opportunity cost $\eta$ (resp. $\gamma$ ) per injured (resp. 12 frivolous) plaintiff. The term (iii) represents the marginal influence of $a$ on the 13 equilibrium probability that a frivolous plaintiff files suit $\left(\right.$ i.e. $\left.\lambda^{*}\right)$, which induces 14 a loss of $\gamma$. Finally, the last term $(i v)$ is simply the marginal cost of advertising 15 incurred by the lawyer.

22 where:

$$
\Sigma_{1}:=p\left(x^{*}\right)\left[\beta \phi(a)+(1-\beta) \psi(a) \lambda^{*}\right] \text { and } \Sigma_{2}:=\beta p\left(x^{*}\right) \phi(a)\left(1-\theta^{*}\right)
$$


1 Following the arguments exposed below, we can show that extending the level of 2 advertising has an ambiguous effect on the social welfare.

First, using (14), we get:

$$
\begin{aligned}
\frac{\partial \Sigma_{1}}{\partial a}:=\overbrace{p\left(x^{*}\right)\left[\beta \phi^{\prime}(a)+(1-\beta) \psi^{\prime}(a) \lambda^{*}\right]}^{(i,+)}+\overbrace{p^{\prime}\left(x^{*}\right) \frac{d x^{*}}{d a}\left[\beta \phi(a)+(1-\beta) \psi(a) \lambda^{*}\right]}^{(i i,-)} & +\underbrace{p\left(x^{*}\right)(1-\beta) \psi(a) \frac{d \lambda^{*}}{d a} \gtreqless 0}_{(i i i,-)} \gtreqless
\end{aligned}
$$

3 Following term $(i)$, advertisement raises the number of suits filed by attracting 4 potential clients (i.e. $\phi^{\prime}(a)>0$ and $\psi^{\prime}(a)>0$ ). However, as captured by $(i i)$ and 5 (iii), advertising also reduces the number of lawsuits because of its positive impact 6 on the injurer's level of care (i.e. $d x^{*} / d a>0$ ), and its deterrent effect on the 7 uninjured plaintiffs' incentives to sue (i.e. $\left.d \lambda^{*} / d a<0\right)$.

8 Second, regarding the effect of advertising on the number of trials, we obtain:

$$
\frac{\partial \Sigma_{2}}{\partial a}:=\overbrace{\beta p\left(x^{*}\right) \phi^{\prime}(a)\left(1-\theta^{*}\right)}^{(i,+)}+\overbrace{\beta p^{\prime}\left(x^{*}\right) \frac{d x^{*}}{d a} \phi(a)\left(1-\theta^{*}\right)}^{(i i,-)} \gtreqless 0
$$

9 This effect is also ambiguous since the number of potential clients is increasing in 10 a (i.e. $\phi^{\prime}(a)>0$ ), while advertising reduces the number of accident victims via 11 its positive effect on the equilibrium level of care (i.e $d x^{*} / d a>0$ ). However, this 12 deterrent effect is welfare-improving also through another channel since the expected 13 damages decreases with the level of advertising (i.e. $\left.p^{\prime}\left(x^{*}\right)\left(d x^{*} / d a\right) \beta l<0\right)$.

${ }_{14}$ Finally, an increase in advertising intensity has two negative effects on the social 15 welfare through its marginal effect on the cost incurred by the lawyer in terms 16 of advertising expenditures (i.e. $h^{\prime}(a)>0$ ), and by the injurer in terms of care 17 spending (i.e. $\left.d k / d a:=k^{\prime}\left(x^{*}\right)\left(d x^{*} / d a\right)>0\right)$.

18 The next proposition follows.

Proposition 3. The impact of advertising intensity on the social cost of accidents is ambiguous:

$$
\frac{\partial L}{\partial a} \gtreqless 0
$$

19 Therefore, a prohibition of lawyer advertising, as adopted in some countries, cannot 20 be optimal in a general sense. Indeed, the trade-offs underlined above imply that 
4 Some additional and interesting comments can be done regarding this welfare analdepending on the different offsetting effects - and promoting advertisement might thus be desirable from a social perspective. ysis. First, comparing (11)-(12) with (13)-(16), it appears a divergence between the equilibrium and socially optimal levels of advertising. This divergence is due to the behavior of the lawyer, who internalizes at equilibrium the settlement/trial fees perceived and the settlement/trial costs incurred (while legal fees are just wealth transfers), but ignores the litigation costs borne both by the plaintiff and the defendant (while these costs are wasteful resources from a social perspective). Accordingly, the offsetting effects depend on the values of the corresponding parameters (i.e. $f$, $f_{s}, f_{t}, c, c_{s}$ and $c_{t}$ ). Second, we can show that frivolous litigation cannot be socially desirable in our model: the occurrence of meritless claims - as captured by $\lambda^{*}-$ increases the social cost of accidents (by enhancing the number of suits filed), without encouraging the injurer to take care ex-ante. Indeed, following (9), the considered mixed-strategy equilibrium implies that the litigation process unfolds as if only legitimate claims were brought. The injurer's expected cost is then not impacted by the potential presence of frivolous plaintiffs. This insight is in stark contrast with Miceli and Stone (2014) who highlight that frivolous litigation may improve welfare precisely by increasing deterrence. The authors get this result by considering an exogenous probability of frivolous suit and analyzing the pure-strategy equilibrium that we chose to rule out. Their conclusion is however interesting since it is counter-intuitive and mitigates the well-known arguments against frivolous suits.

\section{FurTher CONSIDERATIONS}

In this section, we address two extensions of the basic model by considering how the results would change under negligence, rather than strict liability, and English fee-shifting, instead of American rule of cost allocation.

4.1. Negligence. In the previous framework, we assume strict liability, which implies that any legitimate plaintiffs who file suit win their trials with certainty. In contrast, with the negligence rule, plaintiffs will only win if the injurer fails to comply with the due standard of care. For simplicity, we abstract from situations

we might identify some cases where the optimal value of $a$ is strictly positive - 
1 where the rule cannot function perfectly, due for example to legal error (Hylton, 2 1990) or injurer's insolvency (Summers, 1983; Shavell, 1986).

3 As a benchmark, we consider the first-best level of care, denoted $x^{F B}$, which is the 4 solution to the following equation (given the expression of the social cost defined in 5 (13)):

$$
-\left[p^{\prime}(x) \beta l+\frac{\partial \Sigma_{1}}{\partial x}\left(f+c_{s}\right)+\frac{\partial \Sigma_{2}}{\partial x}\left(c_{t}+c\right)\right]=k^{\prime}(x)
$$

6 Using (9), it is straightforward to show that the equilibrium level of care is suboptimal under strict liability (i.e. $x^{*}<x^{F B}$ ), where $x^{*}$ minimizes $k(x)+\beta p(x) \phi(a)(l+c)$. 8 This result highlights that the rule of strict liability under-deters when litigation is 9 costly, which is a well-known issue and arises in our framework for two reasons. First, 10 when choosing his care level, the injurer ignores the plaintiff's filing fee and her at11 torney's litigation costs. Second, when a settlement occurs, the injurer is brought 12 to pay an amount which is lower than the victim's actual loss (i.e. $S:=l-f_{t}<l$ ). 13 In this context, under negligence, the injurer will comply with the due standard $\tilde{x}$ 14 if and only if:

$$
k(\tilde{x}) \leq k\left(x^{*}\right)+\beta p\left(x^{*}\right) \phi(a)(l+c)
$$

where $x^{*}$ is defined above. Therefore, if the due standard is set at the first-best value (i.e. $\tilde{x}=x^{F B}>x^{*}$ ), this condition may or may not be satisfied, implying that the injurer may or may not find optimal to comply. If he does, then the efficient level of care is achieved, while, if he does not, then the negligence standard should be adjusted downward to the point where (18) holds, inducing a suboptimal level of care (equals to $x^{*}$ ).

Overall, under a perfectly working negligence rule, the injurer will meet the due standard of care to avoid liability, and no suits - either legitimate or meritless - will be filed. Indeed, the plaintiff would lose with certainty at trial and, hence, could not expect an agreement to occur at the settlement stage. Anticipating such a situation, the lawyer will not advertise in equilibrium (i.e. $a^{*}=0$ ) since advertising is costly and would be useless: the attorney would not be able to attract any clients since the plaintiffs' expected value of filing a suit is negative.

Proposition 4. Under a well-functioning negligence rule, (i) the injurer complies with the due standard and no plaintiff - either injured or not - files suit; (ii) the injurer takes efficient or too little care; (iii) the lawyer does not invest in advertising, given the absence of any litigation. 
1 In this context, the social cost under negligence is then defined as $k(\tilde{x})+p(\tilde{x}) \beta l$. It 2 implies that the negligence rule should be better-off than strict liability when the due 3 standard is set at $x^{*}$, while the result is ambiguous when $\tilde{x}=x^{F B}$, as summarized 4 in the following proposition.

5 Proposition 5. Switching from strict liability to negligence may improve welfare,

6 depending on the standard of care which is implemented.

Proof. Following (13), the social cost under strict liability is given by:

$$
L=k\left(x^{*}\right)+p\left(x^{*}\right) \beta l+\Sigma_{1}\left(f+c_{s}\right)+\Sigma_{2}\left(c_{t}+c\right)+h(a)
$$

7 where $x^{*}$ is defined by (9) and $\Sigma_{i}$ is stated in (14).

Therefore, when $\tilde{x}=x^{*}$, the social cost under strict liability is higher than the social cost under negligence:

$$
L>k(\tilde{x})+p(\tilde{x}) \beta l \text { with } \tilde{x}=x^{*}
$$

However, this is not necessarily the case when $\tilde{x}=x^{F B}$ :

$$
\begin{gathered}
L<k\left(x^{F B}\right)+p\left(x^{F B}\right) \beta l \\
\Leftrightarrow k\left(x^{F B}\right)-k\left(x^{*}\right)>\left[p\left(x^{*}\right)-p\left(x^{F B}\right)\right] \beta l+\Sigma_{1}\left(f+c_{s}\right)+\Sigma_{2}\left(c_{t}+c\right)+h(a)
\end{gathered}
$$

The intuition behind this result is as follows. Setting $\tilde{x}=x^{*}$ means that the injurer complies with the due standard and chooses the level of care which would be implemented under strict liability. In this case, a switch to the negligence rule is welfare-improving since no litigation or advertising expenditures are incurred, while the cost of care remains unchanged as compared to strict liability. Alternatively, setting $\tilde{x}=x^{F B}$ implies compliance to a greater care (since $x^{F B}>x^{*}$ ). Therefore, the increase in the cost of care due to this higher value of $x$ might more than offset the decrease in the victim's expected loss and the removal of litigation/advertising expenditures, implying that the rule of strict liability would be better-off.

We now turn to another issue which is not addressed in our basic model, that is the possibility of fee-shifting in favor of the winning party. 
4.2. English fee-shifting. The English rule of litigation costs allocation is a primary principle in European systems of civil procedure. ${ }^{13}$ As mentioned in Introduction, this issue is important to investigate since it is often argued that the so-called 'loser-pays rule' should deter frivolous suits. Indeed, this rule allows the victorious litigant to collect his/her litigation costs from the losing party, and should therefore increase the expected cost incurred by uninjured plaintiffs in the lawsuit. In our case, we consider unlimited fee-shifting by assuming full reimbursement of expenditures by the losing party: the plaintiff can recover $f+f_{s}+f_{t}$ in case of winning at trial. ${ }^{14}$ This assumption is not consistent with practice, since courts often impose a limit on recoverable costs (Hyde and Williams, 2002; Carbonara et al., 2015), but it is made for simplicity and could be relaxed without altering the gist of our arguments. Furthermore, we restrict the analysis to the case of strict liability in order to avoid too complex combinations of legal regimes.

Under these assumptions, the English rule makes the injured plaintiff more demanding during the settlement stage since, if a trial occurs, she would incur no costs and her sunk filing/settlement fees would be reimbursed. Indeed, following (2), the minimum settlement offer that this plaintiff would accept is $l-f_{t}$ under the American rule, while it would be $l+f_{s}+f$ under fee-shifting. The next result follows immediately.

Proposition 6. Switching from the English to the American rule lessens both the likelihood of settlement and the probability that an informed frivolous plaintiff files suit:

$$
\theta^{U K}:=\frac{f_{s}+f}{l+f_{s}+f}<\theta^{*} \quad \text { and } \quad \lambda^{U K}:=\frac{\beta \phi(a)\left(f_{t}+c\right)}{(1-\beta) \psi(a)\left(l+f_{s}+f\right)}<\lambda^{*}
$$

where $U K$ refers to the English rule, and $\theta^{*}$ and $\lambda^{*}$ are defined in Lemma 1.

Proof. Considering that the injured plaintiff's settlement threshold is $l+f_{s}+f$ (instead of $l-f_{t}$ ), the proof is similar to the one stated in Lemma 1, and hence omitted.

\footnotetext{
${ }^{13}$ See Bungard (2006) for a survey of the incarnations of this rule in the civil codes of different European countries, such as Belgium, France, Germany, Italy or Sweden.

${ }^{14}$ Notice that the defendant cannot recover his litigation cost $c$ in case of trial since, in our story, a truly injured plaintiff would win with certainty, while a frivolous claim would be dropped at the settlement stage.
} 
1 The intuition behind this proposition is straightforward: the fact that the plaintiff 2 is less prone to settle makes the occurrence of an agreement less likely, which in turn 3 undermines the frivolous plaintiff's incentives to file suit in equilibrium. This result 4 is induced by the transfer of litigation costs to the defendant, allowed by the English 5 rule, which should also distort the level of care that is chosen ex-ante. Indeed, it is 6 easy to show that the equilibrium level of care is higher under fee-shifting since the 7 losing injurer bears greater costs at trial and, hence, is encouraged to take more care 8 in order to reduce the probability of accident. In other words, the injurer's marginal 9 benefit from an increase in care is higher under the English rule, than under the 10 American one, while his marginal cost is unchanged.

11 Proposition 7. Switching from the English to the American rule enhances the equi12 librium level of care.

Proof. Following (9), the equilibrium level of care under the American rule, $x^{*}$, is given by:

$$
-\beta p^{\prime}(x) \phi(a)(l+c)=k^{\prime}(x)
$$

Under the English rule, the injurer's expected cost is:

$$
k(x)+\beta p(x) \phi(a)(l+C)
$$

13 where $C$ is the total cost that he would incur at trial (i.e. $C:=c+f+f_{s}+f_{t}$ ). The injurer's cost-minimizing level of care, $x^{U K}$, is then the unique solution to the following first-order condition:

$$
-\beta p^{\prime}(x) \phi(a)(l+C)=k^{\prime}(x)
$$

14 It follows immediately that $x^{U K}>x^{*}$, since $C>c$.

15 Finally, we can conclude that the overall welfare effect of a switch from the American 16 to the English rule is ambiguous.

17 Proposition 8. Switching from the English to the American rule has an ambiguous 18 effect on the social welfare.

19 This result arises for different reasons. First, it is possible to perceive - without 20 introducing technical details - that the level of advertisement may be positively (or 21 negatively) impacted by a switch to the English rule: as highlighted above, this 
1 rule lessens both the probability of accident and the likelihood of frivolous suits 2 (which pulls down the lawyer's benefit from advertising), but it also decreases the 3 probability of settlement (which provides an opportunity for the lawyer to earn 4 money at trial and, thus, encourages him to advertise). In such a context, both the number of suits filed (i.e. $\Sigma_{1}$ in (13)) and the number of cases going to trial (i.e. $\left.6 \quad \Sigma_{2}\right)$ may increase (or decrease) when fee-shifting is implemented. The value of $\Sigma_{i}$ is 7 indeed deeply impacted by some changes in the advertising intensity, probability of 8 accident, willingness to settle and proportion of meritless claims. However, there is 9 no qualitative impact of fee-shifting on the different marginal effects of advertising, 10 in the extent to which the results stated in Proposition 1, Lemma 2, and Proposition

112 are robust $\left(v i z . d \lambda^{*} / d a<0, d x^{*} / d a>0\right.$ and $\partial \Omega / \partial a \gtreqless 0$ when the English rule is 12 introduced).

\section{Conclusion}

In this paper, we analyze whether the recent trend toward liberalization of legal advertising might be detrimental to social welfare, by studying how the permissibility of solicitations may shape both the defendant's care decisions and the frivolous plaintiff's incentives to file suit. This issue is investigated by considering an asymmetric information setup where the defendant does not know whether the plaintiff's claim is genuine or meritless. Our results suggest that one should be cautious in applying 'common sense' to evaluate the effect of advertising on frivolous lawsuits since we cannot conclude that an increasing reliance on advertisement should necessarily stir-up frivolous litigation. This finding is important since the rent-seeking occasioned by meritless cases is frequently estimated as a major waste of resources by policymakers. From this perspective, we consider that our approach - based on game-theoretic reasoning - may be helpful to understand the strategic implications of advertisement in litigation, and then contributes to the debate on the social desirability of advertising.

However, this simple analysis has only just scratched the surface of the various matters that impinge on this issue, and much more work needs to be done to get a clear picture of the influence of advertising on litigation. In this context, some extensions and generalizations suggest themselves. First, a simplifying but somewhat restrictive assumption is that we develop a screening model in which the uninformed defendant makes a take-it-or-leave-it offer to an informed plaintiff. An interesting 
extension should be to address situations where the plaintiff rather than the defendant makes the settlement offer, such that this offer can serve as a signal for the defendant to infer the validity of the claim. Such a signalling game has been developed, for example, by Reinganum and Wilde (1986) in a different litigation context. Second, a further step would be to extend the present framework by considering a situation where the defendant has substantive information bearing on the case and knows whether the suit is meritless (while the plaintiff is ignorant). For example, we can consider some medical malpractice lawsuits in which the patient/plaintiff has no direct knowledge of what the doctor/defendant did, inducing that the defendant is presumed to know more about the legitimacy of the suit than the plaintiff herself (Bone, 1997). Third, another relevant extension would be to analyze the case of 'ambulance chasing', implying that the lawyer would not target an audience of potential victims but would solicit for clients directly at an accident site. Although this restriction is consistent with practice, since ambulance chasing is prohibited in many countries (e.g. Australia, France), this does not mean it will never be allowed in any jurisdiction at any time. From this standpoint, it would be interesting to extend the analysis - by incorporating ambulance chasers - in order to check for the robustness of our results under an alternative timing of the game.

Finally, from a more general perspective, we might consider that advertising could enhance court congestion, by increasing potentially the number of suits filed, while this overcrowding effect is not captured in our social cost function. To the best of our knowledge, there is no empirical study that links explicitly advertising and delays in public courts. However, as mentioned in Introduction, several papers demonstrate a causality relationship between litigation rates - which is a proxy for court congestion - and the number of lawyers, and we argue that this causality may partially go through the attractive impact of advertisements. Indeed, lawyers may respond to tougher competition - due to a higher offer of legal services - by increasing advertising, which will attract clients and thus favor litigiousness in the legal system. This positive correlation may be illustrated in the U.S. by the decades following the Bates decision, for which we observed both a proliferation of advertisements for legal services and a significant increase in civil lawsuits (Engstrom, 2011). ${ }^{15}$ The likely overcrowding effect of advertising is an important issue from a public policy

\footnotetext{
${ }^{15}$ In the U.S., advertising is allowed since the Supreme Court's ruling in Bates v. Arizona State Bar 433 U.S. 350, 376 (1977).
} 
1 perspective since court delays may adversely affect the efficiency of the judicial

2 system in many ways. Its negative implications may indeed include the plaintiffs

3 welfare loss due to waiting for compensation, the deterioration of evidence, and a

4 reduced time allotted to the scrutiny of settlements by judges whose aim would

5 be to reduce their workload (Helland and Klick, 2007; Shamir and Shamir, 2012).

6 Following this idea and the seminal paper by Gravelle (1990), it would be interesting

7 to modify our model by introducing the possibility for delay, analyzing the behavioral

8 response from litigants, and investigating the welfare implications of advertising in

9 this context. Such an analysis would fill a gap in the literature which considers

10 that court delays are mainly due to inefficiencies of the litigation process and the

11 prevalent cultural norms of the legal environment. 


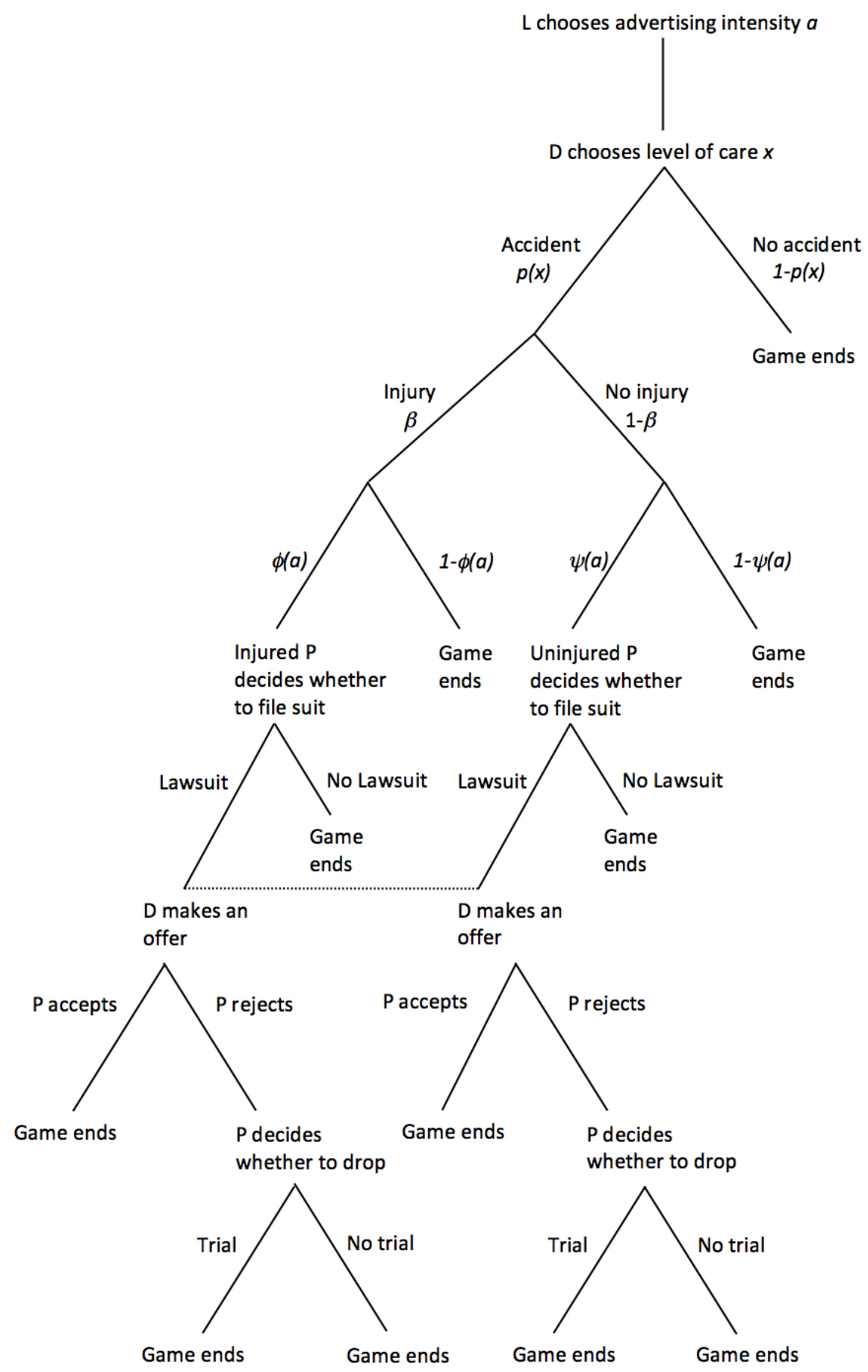

${ }^{16}$ The dotted line indicates imperfect information: it connects two nodes of the game between which the defendant cannot distinguish. 


\section{REFERENCES}

Bagwell, K. (2007). The economic analysis of advertising. In M. Armstrong and R. Porter (eds.), Handbook of Industrial Organization, vol. 3, pp. 1701-1844.

Bebchuk, L. A. (1988). Suing solely to extract a settlement offer. Journal of Legal Studies, 17 (2), 437-450.

Bernstein, A. (2008). Sanctioning the ambulance chaser. Loyola of Los Angeles Law Review, 41 (4), 1545-1584.

Bone, R. G. (1997). Modeling frivolous suits. University of Pennsylvania Law Review, 145, 529-605.

Bungard, B. C. (2006). Fee! fie! foe! fum!: I smell the efficiency of the English rule finding the right approach to tort reform. Seton Hall Legislative Journal, 31 (1).

Buonanno, P. and Galizzi, M. M. (2014). Advocatus, et non latro?: Testing the excess of litigation in the italian courts of justice. Review of Law and Economics, 10 (3), 285-322.

Calvani, T., Langenfeld, J. and Shuford, G. (1988). Attorney advertising and competition at the bar. Vanderbilt Law Review, 41, 761-788.

Carbonara, E., Parisi, F. and von Wangenheim, G. (2015). Rent-seeking and litigation: The hidden virtues of limited fee shifting. Review of Law and Economics, 11 (2), 113-148.

Choi, S. J. (2007). Do the merits matter less after the private securities litigation reform act? Journal of Law, Economics, \& Organization, 23 (3), 598-626.

Emons, W. (2007). Conditional versus contingent fees. Oxford Economic Papers, 59 (1), 89-101.

- and Garoupa, N. (2006). US-style contingent fees and UK-style conditional fees: Agency problems and the supply of legal services. Managerial and Decision Economics, 27 (5), 379-385.

Engstrom, N. F. (2011). Legal access and attorney advertising. Journal of Gender, Social Policy \& the Law, 19 (4), 1083-1094. 
Farmer, A. and Pecorino, P. (1998). A reputation for being a nuisance: Frivolous lawsuits and fee shifting in a repeated play game. International Review of Law and Economics, 18 (2), 147-157.

Ginsburg, T. and Hoetker, G. (2006). The unreluctant litigant? An empirical analysis of japan's turn to litigation. Journal of Legal Studies, 35 (1), 31-59.

Gravelle, H. (1990). Rationing trials by waiting: Welfare implications. International Review of Law and Economics, 10 (3), 255-270.

HAdfield, G. K. (2000). The price of law: How the market for lawyers distorts the justice system. Michigan Law Review, 98 (4), 953-1006.

Helland, E. and Klick, J. (2007). The effect of judicial expedience on attorney fees in class actions. Journal of Legal Studies, 36 (1), 171-187.

Hyde, C. E. (2006). Conditional versus contingent fees: Litigation expenditure incentives. International Review of Law and Economics, 26 (2), 180-194.

— and Williams, P. L. (2002). Necessary costs and expenditure incentives under the English rule. International Review of Law and Economics, 22 (2), 133-152.

Hylton, K. N. (1990). Costly litigation and legal error under negligence. Journal of Law, Economics, \& Organization, 6 (2), 433-452.

Johnson, M., Yazdi, K. and GelB, B. D. (1993). Attorney advertising and changes in the demand for wills. Journal of Advertising, 22 (1), 35-45.

KATz, A. (1990). The effect of frivolous lawsuits on the settlement of litigation. International Review of Law and Economics, 10 (1), 3-27.

Kritzer, H. M. (1990). The Justice Broker: Lawyers and Ordinary Litigation. Oxford University Press.

LANG, L. R. and MARKs, R. B. (1980). Consumers response to advertisements for legal services: An empirical analysis. Journal of the Academy of Marketing Science, 8, 353-373.

Miceli, T. J. and Stone, M. P. (2014). Piggyback lawsuits and deterrence: Can frivolous litigation improve welfare? International Review of Law and Economics, $39,49-57$. 
Millen, D. W. (1992). Consumer Attitudes Toward the Advertising of Professional Services by Accountants, Lawyers, and Physicians, in Perth, Western Australia: An Exploratory Study. Master's thesis, Edith Cowan University.

Mora-Sanguinetti, J. S. and Garoupa, N. (2015). Do lawyers induce litigation? Evidence from spain, 2001-2010. International Review of Law and Economics, 44, 29-41.

Polinsky, A. M. and Rubinfeld, D. L. (1993). Sanctioning frivolous suits: An economic analysis. Georgetown Law Journal, 82, 397-436.

Reinganum, J. F. and Wilde, L. L. (1986). Settlement, litigation, and the allocation of litigation costs. RAND Journal of Economics, 17 (4), 557-566.

Schroeter, J. R., Smith, S. L. and Cox, S. R. (1987). Advertising and competition in routine legal service markets: An empirical investigation. Journal of Industrial Economics, 36 (1), 49-60.

Shamir, J. and Shamir, N. (2012). The role of prosecutor's incentives in creating congestion in criminal courts. Review of Law and Economics, 8 (3), 579-618.

Shavell, S. (1980). Strict liability versus negligence. Journal of Legal Studies, 9 (1), $1-25$.

- (1986). The judgment proof problem. International Review of Law and Economics, 6 (1), 45-58.

Smith, R. E. and Meyer, T. S. (1980). Attorney advertising: A consumer perspective. Journal of Marketing, 44 (2), 56-64.

Stephen, F. H. and Love, J. H. (1996). Deregulation of legal services markets in the UK: Evidence from conveyancing. Human Papers on Public Policy, 4, 53-66.

Stigler, G. J. (1961). The economics of information. Journal of Political Economy, 69 (3), 213-225.

Stone, M. P. and Miceli, T. J. (2012). Optimal attorney advertising. International Review of Law and Economics, 32 (3), 329-338.

Summers, J. (1983). The case of the disappearing defendant: An economic analysis. University of Pennsylvania Law Review, 132, 145-185. 
Tuil, M. and Visscher, L. (2010). New Trends in Financing Civil Litigation in Europe. Edward Elgar.

Willging, T. E. (1988). The rule 11 sanctioning process, Federal Judicial Center. 